\title{
Teoria do Equilíbrio Pontuado: uma análise da execução orçamentária no Brasil no período de 1980-2014
}

Daniel Izaias de Carvalho

Universidade de Brasília (UnB)

Este estudo analisa o comportamento de estabilidade e mudança na execução orçamentária da União, entre 1980 e 2014, buscando verificar a aderência da Teoria do Equilíbrio Pontuado na execução das políticas públicas por meio do orçamento federal. A análise descritiva da execução orçamentária por função indicou um padrão de distribuição das variações com períodos de estabilidade e pequenas interrupções. As maiores amplitudes de variações ocorreram nos anos 1986, 1989 e 1990, coincidindo com períodos de significativas mudanças institucionais. Da mesma forma, a redução na amplitude das variações observadas a partir de 1996 pode indicar alinhamento com a estabilização monetária como fator institucional que contribui para o equilíbrio da execução orçamentária.

Palavras-chave: orçamento público, execução orçamentária, estabilidade econômica, institucionalização

[Artigo recebido em 20 de outubro de 2016. Aprovado em 4 de maio de 2017.] 
Teoría del Equilibrio Puntuado: un análisis de la ejecución presupuestaria en Brasil en el período 1980-2014

Este estudio analiza el comportamiento de estabilidad y cambio en la ejecución presupuestaria del Gobierno Central de Brasil, entre 1980 y 2014, buscando verificar la adherencia de la Teoría del Equilibrio Puntuado en la ejecución de las políticas públicas por el presupuesto federal. El análisis descriptivo de la ejecución presupuestaria por función indicó un estándar de distribución de las variaciones con períodos de estabilidad y pequeñas interrupciones. Las mayores amplitudes de variaciones ocurrieron en los años 1986, 1989 y 1990 , coincidiendo con períodos de significativos cambios institucionales. De la misma forma, la reducción en la amplitud de las variaciones observadas a partir de 1996 puede indicar alineación con la estabilización monetaria como factor institucional que contribuye al equilibrio de la ejecución presupuestaria.

Palabras clave: presupuesto público, ejecución presupuestaria, estabilidad económica, institucionalización

\section{Brazilian budget under Punctuated Equilibrium Theory analysis between 1980-2014}

This study analyzes the trajectory of equilibrium and changes on the budget execution from 1980 to 2014, aiming to verify the validity of the Punctuated Equilibrium Theory to the budgetary decision making process in Brazil. The descriptive statistical analysis of budgetary function variation indicates a pattern of a leptokurtic distribution, characterized by periods of stability with occasionally interruptions. Most significant variations in the years 1986, 1989 and 1990 indicate the possibility that institutional changes may be related to interruptions in periods of balanced budgets. Furthermore, the reduction of variations from 1996 can indicate that the stabilization monetary is an institutional factor that contributes to the balance and budget incrementalism.

Keywords: public budge, budget execution, economic stability, institutionalization 


\section{Introdução}

A análise das políticas públicas pode ser feita sob diversas lentes teóricas, como: o incrementalismo, múltiplos fluxos, o equilíbrio pontuado, coalizões de defesa e institucionalismo (BONAFONT, 2004). O processo contínuo de negociação social e política converge para a definição da forma como os recursos públicos serão aplicados na implementação de políticas públicas. Dessa forma, o orçamento público representa um movimento mais complexo do que a simples previsão de receitas e definição de despesas.

Entender a dinâmica e os padrões de mudanças na execução das políticas públicas ao logo do tempo, por meio das variáveis orçamentárias, permite reconhecer o orçamento público como instrumento de análise de políticas públicas. Sendo assim, este estudo usou informações orçamentárias, sob um enfoque teórico, para analisar a execução orçamentária das políticas públicas.

A Teoria do Equilíbrio Pontuado explica o comportamento de estabilidade e mudança nos processos políticos em relação à trajetória anterior, enquanto a maior parte dos modelos teóricos concentra-se em explicar a estabilidade ou a mudança nas políticas públicas (TRUE et al., 2007). A Teoria do Equilíbrio Pontuado, por sua vez, busca explicar tanto a estabilidade como a mudança.

Analisar as políticas executadas no orçamento público, sob a perspectiva do equilíbrio pontuado, permite detectar as mudanças de larga escala ao longo de um processo estável de execução orçamentária para, dessa forma, colocar luz sobre esses momentos de mudanças bruscas ("terremoto") e compreender esses processos.

Com isso, o objetivo deste artigo foi o de analisar sob o enfoque da Teoria do Equilíbrio Pontuado a execução orçamentária no Brasil, para identificar os períodos de equilíbrio e de interrupção desses equilíbrios nas diversas áreas do Governo Federal. Para tanto, foi realizado um estudo sobre as variações anuais da execução orçamentária por função, do orçamento da União, entre os anos de 1980 e 2014.

Além desta introdução e da conclusão, o artigo apresenta uma descrição do quadro teórico sobre o comportamento de estabilidade e interrupção do equilíbrio na execução de políticas públicas por meio do orçamento. Em seguida, são apresentados os procedimentos metodológicos adotados para desenvolvimento do estudo e, por fim, são discutidos os resultados do estudo empírico à luz do modelo de análise proposto.

\section{Referencial teórico}

As decisões orçamentárias dependem da escolha de alternativas em um ambiente de extraordinária complexidade, em que um grande número de programas 
é considerado, mas há grande dificuldade em predizer as consequências na escolha ou mudança de alternativas (DAVIS; DEMPSTER; WILDAVSKY, 1966).

Os principais modelos teóricos oriundos da noção de racionalidade limitada de Simon $(1957,1977,1983,1985)$ que analisam o processo de mudança e estabilidade em políticas públicas são: a Teoria Incremental, a Teoria de Múltiplos Fluxos e a Teoria do Equilíbrio Pontuado. O foco da teoria incrementalista é a mudança marginal em relação à base orçamentária. Esse modelo tem permanecido quase que inalterado ao longo do tempo (SWAIN; HARTLEY, 2001). Davis, Dempster e Wildavsky (1966) afirmam que a base orçamentária é o valor autorizado pelo congresso no ano anterior. Sendo assim, o incrementalismo funciona como neutralizador de impactos e reduz efeitos de alterações políticas e sociais, ou seja, sua utilização defende o status quo contra as demandas por mudanças da relação política e orçamentária.

O incrementalismo não é apenas um método de cálculo que consiste em medir a variação a partir de um valor padrão, mas também um mecanismo de tomada de decisão que busca mudar progressivamente a realidade baseada em consenso. Os partidos políticos e líderes que alcançam o poder coincidem em ideias fundamentais em torno da governabilidade, embora tenham divergências em políticas setoriais. Quando ocorre alternância de lideranças por meio das eleições, as políticas desenhadas pelo novo governo revisam aquelas aplicadas pelo antecessor (FONTAINE, 2015).

De acordo com Lindblom (1959), as escolhas políticas ocorrem de maneira sequencial e são feitas/refeitas para atingir objetivos que também mudam diante de novas considerações. Com isso, é necessário realizar acordos mútuos para manter os interesses dos atores envolvidos na definição das políticas públicas. Embora os atores envolvidos atuem na manutenção de políticas já existentes com variação marginal, políticas não incrementais podem ser implementadas.

O processo político é uma adaptação, no qual as soluções experimentadas são revisadas e melhoradas constantemente em função dos resultados que produzem. Nesse sentido, as políticas resultam mais da arte de um governo em ajustar as políticas do que em governar por sucessivas escolhas racionais (LINDBLOM, 1959).

Dessa forma, uma das principais críticas ao Modelo Incremental é a de que ele não permite analisar e explicar mudanças bruscas que se observam em análises históricas (Ollaik; Wenceslau; SerPA; Medeiros, 2011). As mudanças bruscas são apontadas por Davis, Dempster e Wildavsky (1966) como troca de presidente; alteração de posicionamento das agências, seja por perda de confiança e legitimidade ou por ocupar novos espaços; situações de crises; entre outras.

Nesse sentido, ao analisar os setores de transporte e saúde no âmbito federal nos Estados Unidos, Kingdon (2011) propôs o Modelo de Múltiplos Fluxos para 
compreender o processo de mudança na implementação de políticas, que aponta três fluxos importantes que devem ser levados em consideração no processo decisório: problems, policies e politics. O Modelo de Múltiplos Fluxos é adotado como uma referência teórica para vários estudos vinculados à análise da formulação de políticas e apresenta a ideia de que os problemas (problems) são construídos social/politicamente e existem a partir do momento em que os formuladores de políticas públicas tomam conhecimento da sua existência e passam a pensar na possibilidade de uma solução. Já o fluxo de políticas públicas (policies) é um conjunto de alternativas para problemas políticos, ou seja, é onde novas políticas são moldadas (ZAHARIADIS, 2007). Nesse fluxo, apenas idéias com factibilidade técnica e aceitabilidade política sobrevivem (OlLAIK; WENCESLAU; SERPA; MEDEIROS, 2011). O fluxo político (politics) tem grande influência na alteração da agenda governamental, seja pelo humor nacional (national mood) ou pela alternância de atores políticos (turnover), e pode promover oportunidade de mudança pela janela de oportunidade (policy windows), que Kingdon (2011) apresenta como circunstâncias que possibilitariam a convergência dos múltiplos fluxos (problem, policy e politics). Cabe observar que diversos atores participam desses fluxos, como: o Presidente da República, membros do Congresso, servidores públicos, lobistas, jornalistas, acadêmicos, entre outros.

Assim, o Modelo de Múltiplos Fluxos busca trabalhar o entendimento da complexidade de construção de agenda, percepção de problemas governamentais, instituições políticas, políticas públicas, participantes ocultos e visíveis, empreendedores, janelas de oportunidade e agenda de decisão (KINGDON, 2011).

Kingdon (2011) afirma que a apresentação definida e articulada de um problema, por um dos mais variados atores, é o elemento central para tentar influenciar a agenda, e ocorre por meio da utilização de indicadores, crises, desastres ou feedbacks das ações governamentais. Os indicadores podem ser representados por um índice de acesso a um determinado serviço, os desastres podem ser caracterizados por enchentes ou alagamentos, uma crise pode ser provocada por denúncias de desvio de verbas de um determinado programa de governo e os feedbacks representam a atuação governamental diante de uma situação crítica. Sendo assim, esses elementos podem possibilitar a articulação ou definição de um problema, no Modelo de Múltiplos Fluxos, para alcançar a agenda governamental.

Com o surgimento das janelas políticas ou janelas de oportunidade, que representam o momento propício ao acoplamento dos três fluxos (problema, alternativas e política), pode ocorrer a conexão entre as alternativas e os problemas que entraram na agenda governamental. Para Kingdon (2011), as janelas derivam de fatores como: processos cíclicos, crises, mudanças de governo, mudança de lideranças no congresso, alteração de gestores de órgãos e empresas, reformulação 
de programas e ações governamentais, entre outros. Nesse momento, o empreendedor de políticas públicas busca influenciar a convergência dos fluxos e a promoção de determinada alternativa.

O Modelo de Múltiplos Fluxos pode representar lentes, perspectivas ou quadros para explicar como as políticas são formuladas em condições de ambiguidade, e sua utilização como instrumento de análise pode alcançar o escopo nacional, supranacional e subnacional (ZAHARIADIS, 2007).

Embora o Modelo de Múltiplos Fluxos analise e descreva como uma política entra na agenda governamental, Zahariadis (2007) argumenta que essa perspectiva não gera hipóteses falsificáveis ou quantitativamente examináveis. Entretanto, ele também reconhece que o modelo possui algum grau de previsibilidade e aplicabilidade.

Ao observar de forma combinada o Modelo Incremental e o de Múltiplos Fluxos, percebe-se que processo de elaboração de políticas públicas é direcionado pela lógica da estabilidade incremental, mas que ocasionalmente esse processo produz grandes mudanças em relação a uma política anterior.

A estabilidade e a mudança são elementos importantes para analisar o processo de elaboração das políticas públicas. Alguns modelos de análise foram desenvolvidos para explicar a estabilidade (Modelo Incremental) ou a mudança (Teoria dos Múltiplos Fluxos). Por sua vez, a Teoria do Equilíbrio Pontuado busca contemplar tanto a estabilidade quanto a mudança de políticas públicas (BRYAN; BAUMGARTNER; JONES, 2007).

A Teoria do Equilíbrio Pontuado analisa esses movimentos no processo das políticas públicas a partir de uma base teórica dupla, que contempla as instituições políticas e o processo decisório a partir da racionalidade limitada. A principal explicação para essa característica do processo de políticas públicas advém da interação de instituições políticas de diversos níveis e o processo decisório marcado pela racionalidade limitada, criando padrões de estabilidade e mobilização. Essa teoria enfatiza dois elementos relacionados ao processo de políticas: a definição do issue e o estabelecimento da agenda. Um issue, ou questão de política, é definido pelo discurso público e, na medida em que entra ou sai da agenda, definições de políticas públicas podem ser reforçadas ou questionadas (BRYAN; BAUMGARTNER; JONES, 2007).

O termo equilíbrio pontuado foi cunhado em 1972 pelos paleontólogos Nile Eldredge e Stephen Jay Gould, no ensaio Models of Paleobiology, para descrever que a mudança evolucionária biológica não ocorre sempre de maneira lenta e constante como defendida por Charles Darwin (GIVEL, 2010). Em 1993, Baumgartner e Jones adotaram a terminologia do equilíbrio pontuado, argumentando que as políticas 
públicas têm uma dinâmica de mudança incremental e de longo prazo, seguida por choques externos aos monopólios políticos, resultando em reorientação ou mudanças políticas de larga escala. Com isso, após a pontuação do equilíbrio, as políticas serão orientadas por novos padrões incrementais de mudança no longo prazo (GIVEL, 2010).

De acordo com Baumgartner e Jones (1993), o processo político é direcionado pela lógica da estabilidade e incrementalismo, mas ocasionalmente esse processo produz grandes mudanças em relação a uma política anterior, ruptura essa chamada de "terremoto" pelos autores. Sendo assim, longos períodos de estabilidade nas políticas públicas, em que as mudanças se processam de forma lenta, incremental e linear, são interrompidos por momentos de rápida mudança (CAPELLA, 2006).

Ademais, a teoria do equilíbrio pontuado busca avaliar esse movimento combinado de crescimento marginal com a mudança em larga escala, que resulta de uma interação entre multiníveis de instituições políticas e do comportamento dos tomadores de decisão, estabelecendo padrões de estabilidade e/ou mobilizações para pontuar o equilíbrio (BRYAN; BAUMGARTNER; JONES, 2007).

Os autores acrescentam ainda que a dificuldade dos grupos desfavorecidos e das novas ideias em alterar o sistema de decisão política estabelecido é justificada pelos suaves e moderados ajustes circunstanciais da política orientados por grupos conservadores que se esforçam para manter o status quo das políticas nacionais.

Quando Baumgartner e Jones (2003) analisaram, nos Estados Unidos, a formulação de políticas públicas, observaram que: (1) a elaboração das políticas convergia tanto para a estabilidade como para a mudança em larga escala; (2) as instituições americanas reforçam essa tendência de equilíbrio pontuado; e (3) a imagem da política (policy image) tem um papel fundamental na expansão das questões de políticas para além dos especialistas ou grupos responsáveis pelo monopólio do tema da política (policy monopoly).

Ainda, analisando o ambiente de tomada de decisão e execução de políticas públicas nos Estados Unidos, Baumgartner e Jones (1991 e 1993) perceberam a existência de características institucionais que reforçam o equilíbrio pontuado: a separação entre instituições, a sobreposição entre jurisdições e uma relativa abertura à mobilização social. Esses aspectos criam uma dinâmica entre a política do subsistema de política pública e a macropolítica do Congresso, que ora reforçaria o status quo, ora iria contra ele (BRYAN; BAUMGARTNER; JONES, 2007).

Focada na interação entre as instituições políticas, mobilização de interesse e racionalidade limitada na tomada de decisão, a teoria do equilíbrio pontuado foi utilizada, inicialmente, para realizar a análise de longo prazo da formulação da política nacional dos Estados Unidos. Entretanto, suas características também 
podem ser úteis na compreensão da formulação de políticas públicas de forma geral (BRYAN; BAUMGARTNER; JONES, 2007).

Com base na racionalidade limitada de Herbert Simon $(1957,1977,1983,1985)$ e no processamento paralelo e serial de informações para tomada de decisões individuais e organizacionais, Jones (1994) afirma que o sistema político, assim como o humano, não consegue analisar todas as demandas políticas em discussão. Dessa forma, os subsistemas do sistema político podem ser vistos como um mecanismo que permite a discussão paralela de vários temas, simultaneamente, com as respectivas comunidades de especialistas de cada tema.

Questões processadas nos subsistemas seguem uma política de ajustamento com alterações incrementais resultante de barganhas entre os interessados para enfrentar circunstâncias de mudança, ou seja, o processo paralelo trabalha contra os processos de mudança de larga escala. Em determinados momentos, o processamento de questões paralelas é interrompido e alçado ao processamento serial da macropolítica, cujo locus no caso americano foi o Congresso e a Presidência da República (BRYAN; BAUMGARTNER; JONES, 2007). Na macropolítica as decisões são seriais, ou seja, um problema é discutido por vez, o que limita a quantidade de temas na agenda. Contudo, é nesse ambiente que as maiores mudanças ocorrem, pois, ao alcançar a agenda da macropolítica, o tema em discussão necessita de uma solução não incremental (BRYAN; BAUMGARTNER; JONES, 2007).

Embora seja requisito para a mudança pontuada, o fato de um determinado problema sair do seu subsistema e acessar a agenda da macropolítica não garante a mudança ou a quebra do monopólio político sobre o tema. O monopólio da política é definido como estrutura institucional responsável por definir as políticas sobre questões de uma determinada área, legitimada pela imagem da política construída sobre a questão e sustentada por uma ideia forte, conectada a valores centrais e que pode ser comunicada publicamente de forma simples (BRYAN; BAUMGARTNER; JONES, 2007).

O sucesso de um subsistema na definição de políticas suaviza as pressões por mudanças, assegurando a estabilidade ou a mudança de modo incremental. O comportamento de estabilidade adotado nos monopólios políticos está relacionado ao que Baumgartner e Jones (1993) denominam processo de feedback negativo, que tende a reforçar o status quo, evitando mudanças significativas, mantendo os acordos institucionais constantes e um ritmo lento de mudanças. Bryan, Baumgartner e Jones (2007) apontam que as contínuas interações dentro de subsistemas de política podem evitar a interrupção de políticas por meio de estratégias de gestão de conflitos. Com isso, os arranjos institucionais podem afetar a magnitude de pontuações. 
Contudo, a estabilidade na formulação e condução de políticas públicas observada nos subsistemas ou monopólios políticos não é imune a colapsos (BRYAN; BAUMGARTNER; JONES, 2007). As pressões por mudanças na condução de um tema sob a jurisdição de um subsistema podem incluir novos atores e instituições governamentais na reorganização e definição de novas políticas.

Nesse sentido, a alteração da imagem da política pode retirar a legitimidade de um determinado subsistema para conduzir as políticas de uma determinada área, quebrando um monopólio e elevando esse tema do subsistema para a macropolítica. A imagem da política (um misto de informação empírica, crenças e apelos emotivos) enquadra as políticas sobre determinado tema e pode atrair ou afastar atores, espaços de discussão e empreendedores políticos nos processos positivos de feedback (BRYAN; BAUMGARTNER; JONES, 2007).

Baumgartner e Jones (1993) explicam que as mudanças em grande escala na política resultam da interação de imagem política e instituições, ou seja, quando uma imagem é contestada e o monopólio político está sob ataque, cresce a possibilidade de novas mobilizações que levem o tema para a agenda macropolítica.

Ao alcançar a macropolítica, em que atuam outros atores legitimados na reforma institucional, dá-se espaço a um novo equilíbrio de forças políticas, e o domínio de um subsistema sobre um determinado tema é rompido. A macropolítica é a política da pontuação, de mudanças em larga escala, da competição entre imagens de políticas públicas, manipulação política e de feedbacks positivos, que potencializam impulsos de mudança. Na presença de feedbacks positivos, mesmo uma mudança pequena nas condições do processo da política pode desencadear mudanças rápidas e intensas na política pública (BRYAN; BAUMGARTNER; JONES, 2007).

Uma das formas mais tradicionais de aplicação empírica do modelo é a análise de mudanças na alocação orçamentária ao longo do tempo. Ao estender a teoria do equilíbrio pontuado para o orçamento americano, Jones, Baumgartner e True (2012) reforçam a ideia de que as decisões governamentais passam por processos paralelos (subsistemas, monopólio político e incrementalismo) ou seriais (ambiente da macropolítica com atenção nacional do Congresso/Presidência, monopólio da política em constatação e grandes mudanças). A escolha orçamentária é multifacetada, marcada por limitações cognitivas e a racionalidade limitada.

A literatura empírica e teórica sobre orçamento público aponta para a ocorrência de pontuações causadas por fatores exógenos (OSTROM; MARRA, 1986), porém Bryan, Baumgartner e Jones (2012) apontam que tanto mobilizações endógenas como choques exógenos podem provocar mudanças bruscas. Esses fatores podem ser representados pela mudança no nível de atenção sobre a política em questão, surgimento de novas informações e mudança na composição do corpo de tomadores de decisão. 
Bryan, Baumgartner e Jones (2007) analisaram as variações orçamentárias ao longo do tempo enquanto processos estocásticos, verificando um padrão de distribuição leptocúrtico das alterações orçamentárias. Isto é, identificou-se uma distribuição univariada com um pico central delgado, com a grande maioria das modificações orçamentárias concentradas em variações nulas ou próximas de zero. Ou seja, o período de estabilidade nas políticas é a regra.

Contudo, eles também identificaram, no estudo, alterações significativas no orçamento, com saltos que podem chegar a $100 \%$ de um ano para outro. Essas pontuações ou interrupções no padrão de evolução incremental no orçamento são percentualmente raras, como indicam as longas caldas na representação gráfica da distribuição. Levantam, ainda, a hipótese de que a distribuição não normal para as variações anuais do orçamento seja evidenciada em todos os níveis de agregação orçamentária (programas, funções, subfunções e agências). Estatisticamente, as variações orçamentárias mostram-se semelhantes aos movimentos de placas tectônicas, que se mostram relativamente estáveis na maior parte do tempo, com a ocorrência de terremotos, mudanças significativas, em alguns momentos.

Para testar a não normalidade das variações orçamentárias, Bryan, Baumgartner e Jones (2007) trataram por subfunções ${ }^{1}$ os dados orçamentários dos anos fiscais de 1947 até 2003, fornecidos pela U.S. Budget Authority para o Office of Management and Budget (OMB). Os dados foram corrigidos pela inflação e tratados de forma a superar os problemas de comparabilidade ao longo do período selecionado. A distribuição encontrada foi claramente leptocúrtica, indicando uma forte frequência de pequena variação orçamentária, poucas variações moderadas e caudas indicando fortes variações, conforme prevê a Teoria do Equilíbrio Pontuado.

Bryan, Baumgartner e Jones (2007) apontam que esse modelo tem se mostrado robusto para vários estudos dentro e fora dos Estados Unidos: Jordan (2003 apud BAUMgARTNER; JONES; TRUE, 2007) encontrou pontuações na distribuição de variação orçamentária para gastos locais nos Estados Unidos; Robinson (2004 apud BAUMgARTNER; JONES; TRUE, 2007), para as escolas do distrito do Texas; Breunig e Koske (2005 apud BAUMGARTNER; JONES; TRUE, 2007), para orçamentos estaduais; Jones e Baumgartner (2005), para as despesas nacionais dos Estados Unidos desde o ano de 1800. O padrão também apareceu em estudos realizados em outros países como: Reino Unido (John; MARgetTS, 2003; SOROKA; WLeZIEN; McLean, 2006), Dinamarca (BReunig, 2006; Mortensen, 2005), Alemanha (BREUnig, 2006), França (BAumgartner; Françols; Foucault, 2006) e Bélgica (WALgrave, 2005).

\footnotetext{
${ }^{1}$ Das setenta e seis subfunções do OMB que contemplam as 20 principais funções do governo, foram eliminadas dezesseis subfunções financeiras e sessenta foram usadas como variáveis orçamentárias.
} 
Embora a Teoria do Equilíbrio Pontuado considere os períodos de mudanças bruscas e de rápidas transformações, que representam pontuações em períodos de estabilidade, ainda parece melhor para explicar o passado do que para prever o futuro. A necessidade da observação de longos períodos de execução orçamentária para identificar as interrupções do equilíbrio e a dificuldade no uso da teoria para predizer o futuro são algumas de suas limitações. Dessa forma, a estratégia de pesquisa é estudar longos períodos de tempo para compreender e identificar os períodos de estabilidade e de pontuação do equilíbrio (OLLAIK et al., 2011).

No contexto brasileiro, os estudos orçamentários geralmente focalizam aspectos legais, técnicos e administrativos e não utilizam modelos teóricos que poderiam contribuir para a análise das políticas públicas (OLLAIK et al., 2011). Assim, não são muitos os estudos que analisam o orçamento brasileiro à luz da Teoria do Equilíbrio Pontuado.

Abreu et al. (2012) analisaram as variações orçamentárias por programas do plano plurianual (PPA) a partir dos projetos de lei orçamentária enviados pelo Executivo ao Legislativo entre 2004 e 2010. A distribuição das variações nas propostas orçamentárias no período aponta um padrão leptocúrtico, não normal, evidenciando a predominância de períodos de estabilidade e incrementalismo orçamentário, interrompidos por "terremotos". As maiores médias e desvios padrão das variações foram identificados nos primeiros anos de vigência dos PPAs, indicando a possibilidade de que as mudanças nas políticas tendem a ser influenciadas por alterações na agenda política resultantes do processo eleitoral. Contudo, o período de oito anos analisado é relativamente curto, e os dados da proposta orçamentária indicam apenas parte da decisão alocativa, visto o caráter autorizativo do orçamento, que ainda é alterado no processo legislativo e ao longo de sua execução.

A dimensão orçamentária também tem sido utilizada para analisar os processos de estabilidade e mudanças em áreas de políticas públicas no Brasil, entendendo que grandes impactos financeiros na alocação de recursos orçamentários são explicados por fortes mudanças no direcionamento das políticas públicas (SILVA et al., 2016). Nesse sentido, Silva et al. (2016) analisam a correlação entre as variações no orçamento das políticas voltadas para a criança e o adolescente e a formação da imagem da política indicada pela cobertura da mídia sobre o tema entre 1994 e 2011. O estudo identifica que há uma correlação significativa, ainda que fraca, entre a cobertura da mídia e as variações orçamentárias na área.

Em outra abordagem da análise do orçamento a partir da Teoria do Equilíbrio Pontuado, Silvestre e Araújo (2015) apontam para a existência de períodos de estabilidade e de fortes variações nos orçamentos de investimento dos municípios 
cearenses entre 2006 e 2010. Argumenta-se que as pontuações nesse caso não são decorrentes de variáveis econômicas, mas sim dependentes das transferências de recursos da União. Contudo, o horizonte temporal é restrito, limitando as conclusões do trabalho.

\section{Método}

A hipótese central deste trabalho é de que a execução de políticas públicas, por meio da execução orçamentária, no Brasil, é estável ao longo do tempo e apresenta poucas variações atípicas. Desse modo, como forma de verificar a aderência da Teoria do Equilíbrio Pontuado às variações orçamentárias no Brasil, propõe-se analisar a distribuição das variações na execução por função orçamentária ao longo de um período de 35 anos - entre 1980 e 2014.

Uma vez verificada uma distribuição de frequência de variação da execução orçamentária das funções com padrão leptocúrtico e não normal, é possível inferir que a Teoria do Equilíbrio Pontuado possui aderência ao processo de alocação de recursos orçamentários no Brasil. Para essa análise das variações anuais da execução orçamentária por função, serão utilizadas ferramentas de estatística descritiva, como histogramas, testes de normalidade e diagramas de boxplot (caixa e bigodes).

A identificação das variações atípicas é uma importante etapa deste estudo, pois estas representam a interrupção do equilíbrio. Para evitar a subjetividade de atribuir um percentual mínimo de variação como sendo a interrupção do equilíbrio, este trabalho utilizará as variações atípicas. Embora as variações atípicas estejam apresentadas de forma resumida na Tabela 6 , este estudo se prenderá às variações superiores a $200 \%$ como objeto de análise.

Considerando-se o caráter autorizativo do orçamento brasileiro e as não raras alterações orçamentárias ao longo de cada exercício financeiro, entende-se que a informação que melhor indica as decisões alocativas é a de execução orçamentária. Nesse sentido, a opção metodológica deste trabalho é pela utilização dos dados da execução da despesa, entendida como a despesa liquidada, desconsiderados os restos a pagar não processados.

A origem dos dados é o Sistema Integrado de Administração Financeira do Governo Federal (Siafi) (entre 1987 e 2014) e o Balanço Geral da União (BGU) (entre 1980 e 1986). A série histórica com valores atualizados pelo Índice Geral de Preços (IGP-DI) para janeiro de 2015 é divulgada pela Secretaria do Tesouro Nacional², de modo que se trata de uma fonte de dados secundária.

\footnotetext{
${ }^{2}$ A base de dados pode ser obtida no endereço eletrônico da Secretaria do Tesouro Nacional http://www.tesouro. fazenda.gov.br/-/series-historicas. $\mathrm{O}$ acesso aos dados utilizados neste trabalho foi realizado em 16 de outubro de 2015.
} 
A categoria principal de análise dos dados é a função orçamentária, que é o nível mais amplo de agregação do orçamento. Apesar de sua amplitude, é importante ressaltar que a função é a categoria que se manteve mais estável no período e, portanto, a única que permite uma análise comparada de longo prazo.

Considerando as alterações na estrutura das funções ocorridas em 1994 e, especialmente, em 2001, os dados foram tratados para que pudessem manter sua comparabilidade ao longo dos anos. Para tanto, buscou-se compatibilizar a execução orçamentária para a estrutura funcional vigente em 2016, que foi o ano da pesquisa. Foram, portanto, consideradas 15 funções governamentais, conforme demonstra a Tabela $1^{3}$.

Tabela 1 - Compatibilização da classificação funcional ${ }^{4}$

\begin{tabular}{|c|c|c|}
\hline $\begin{array}{c}\text { Classificação funcional } \\
\qquad 1980-2000\end{array}$ & $\begin{array}{c}\text { Classificação funcional } \\
\text { 2001-2014 }\end{array}$ & $\begin{array}{c}\text { Classificação funcional } \\
\text { compatibilizada } \\
1980-2014\end{array}$ \\
\hline Legislativa & Legislativa & Legislativa \\
\hline Judiciária & $\begin{array}{l}\text { Judiciária } \\
\text { Essencial à Justiça }\end{array}$ & Judiciária \\
\hline $\begin{array}{l}\text { Administração e } \\
\text { Planejamento }^{3}\end{array}$ & $\begin{array}{l}\text { Administração } \\
\text { Direitos da Cidadania } \\
\text { Ciência e Tecnologia }\end{array}$ & $\begin{array}{l}\text { Administração e } \\
\text { Planejamento }\end{array}$ \\
\hline $\begin{array}{l}\text { Administração } \\
\text { e Planejamento } \\
\text { - Refinanciamento }\end{array}$ & $\begin{array}{l}\text { Encargos Especiais }^{2} \\
\text { Encargos Especiais } \\
\text { - Refinanciamento }\end{array}$ & Excluída \\
\hline Agricultura & $\begin{array}{l}\text { Agricultura } \\
\text { Organização Agrária }\end{array}$ & Agricultura \\
\hline Comunicações & Comunicações & Comunicações \\
\hline $\begin{array}{l}\text { Defesa Nacional e } \\
\text { Segurança Pública }\end{array}$ & $\begin{array}{l}\text { Defesa Nacional } \\
\text { Segurança Pública }\end{array}$ & $\begin{array}{l}\text { Defesa Nacional e } \\
\text { Segurança Pública }\end{array}$ \\
\hline Desenvolvimento Regional & ---- & Excluída \\
\hline
\end{tabular}

\footnotetext{
${ }^{3}$ Para fins de documentação e verificação detalhada do processo de compatibilização e tratamento dos dados, o arquivo em Excel (formato XLXS) da base de dados original e final, assim como de todo o processo de compatibilização dos valores pode ser acessado por meio do link: https://docs.google.com/spreadsheets/d/1ary NZo90598Snt95ob7Fs7oDITWYq31ElpsU-OZW9CE/pub?output=xlsx.

${ }^{4}$ Para que essa compatibilização fosse possível, foram excluídas as funções de natureza financeira (refinanciamento da dívida), tal qual foi realizado em Bryan, Baumgartner e Jones (2007). A função Desenvolvimento Regional foi excluída, uma vez que foi extinta em 2001 e não se verificou, nas leis orçamentárias seguintes, a continuidade de suas ações, não sendo possível enquadrar sua despesa em nenhum das funções vigentes a partir de 2000.
} 


\begin{tabular}{|c|c|c|}
\hline Classificação funcional & Classificação funcional & $\begin{array}{l}\text { Classificação funcional } \\
\text { compatibilizada }\end{array}$ \\
\hline $1980-2000$ & 2001-2014 & $1980-2014$ \\
\hline \multirow{3}{*}{ Educação e Cultura } & Educação & \multirow{3}{*}{ Educação e Cultura } \\
\hline & Cultura & \\
\hline & Desporto e Lazer & \\
\hline $\begin{array}{l}\text { Energia e Recursos } \\
\text { Minerais }\end{array}$ & Energia & $\begin{array}{l}\text { Energia e Recursos } \\
\text { Minerais }\end{array}$ \\
\hline \multirow{2}{*}{ Habitação e Urbanismo } & Urbanismo & \multirow{2}{*}{ Habitação e Urbanismo } \\
\hline & Habitação & \\
\hline \multirow{2}{*}{$\begin{array}{l}\text { Indústria Comércio e } \\
\text { Serviços }\end{array}$} & Indústria & \multirow{2}{*}{$\begin{array}{l}\text { Indústria Comércio e } \\
\text { Serviços }\end{array}$} \\
\hline & Comércio e Serviços & \\
\hline Relações Exteriores & Relações Exteriores & Relações Exteriores \\
\hline \multirow{3}{*}{ Saúde e Saneamento } & Saúde & \multirow{3}{*}{ Saúde e Saneamento } \\
\hline & Saneamento & \\
\hline & Gestão Ambiental & \\
\hline Trabalho & Trabalho & Trabalho \\
\hline \multirow{2}{*}{ Assistência e Previdência } & Assistência Social & \multirow{2}{*}{ Assistência e Previdência } \\
\hline & Previdência Social & \\
\hline Transporte & Transporte & Transporte \\
\hline
\end{tabular}

Fonte: Elaboração própria.

\section{Análise empírica das variações da execução orçamentária federal por função entre 1980 e 2014}

Para fins desta análise descritiva, não são considerados os valores reais da execução orçamentária, mas as variações percentuais ano a ano dos valores reais da execução por função. Nesse sentido, a série histórica das variações possui 34 variações entre 1980 e 2014 (1980/1981, 1981/1982, ... 2013/2014) para cada uma das quinze funções, perfazendo uma base de dados com um total de 510 valores de variações.

A partir dos valores visualizados na Tabela 2, observa-se que os valores da média e da mediana das variações anuais da execução orçamentária por função entre 1980 e 1981 são baixos e indicam uma posição de estabilidade. Contudo, as variações máximas e mínimas, bem como o valor relativamente alto do desvio padrão indicam a existência não rara de variações significativas. Dessa forma, verificar o comportamento da variação na execução orçamentária por função à luz da Teoria do Equilíbrio Pontuado exige um aprofundamento da análise descritiva desses dados. 
Tabela 2 - Valores máximo, mínimo, da média, mediana e desvio padrão das variações anuais da execução orçamentária por função 1980-1981

\begin{tabular}{cc}
\hline Máximo & $848,36 \%$ \\
Mínimo & $-94,17 \%$ \\
Média & $13,80 \%$ \\
Mediana & $2,87 \%$ \\
Desvio Padrão & $76,72 \%$ \\
\hline
\end{tabular}

Fonte: Elaboração própria.

O diagrama de boxplot (caixa e bigodes) permite identificar e analisar a variação de uma variável, no caso, a variação da execução orçamentária anual por função, entre diferentes conjuntos de dados. Os limites da caixa são formados pelos quartis inferior e superior do conjunto, de modo que a caixa mostra $50 \%$ das variações situados no meio do conjunto de valores (denominado intervalo interquartílico). A reta horizontal no interior da caixa representa a mediana do conjunto. Por sua vez, as linhas que conectam a base inferior e superior da caixa (bigodes) representam os valores que estão nos primeiro e último quartis do conjunto. O tamanho da linha superior (inferior) é indicado pelo que for menor (maior) entre o maior (menor) valor do conjunto e resultado do limite superior (inferior) adicionado (subtraído) de uma vez e meia a altura da caixa. Quando os valores máximos e mínimos do conjunto não forem os limites das linhas, estes são considerados outliers e representados por asteriscos (FIELD, 2010).

A título de exemplo, o diagrama de boxplot na Figura 1 representa o conjunto das variações médias anuais entre 1980 e 2014. Nesse diagrama, não há outliers, de modo que a distância entre a linha horizontal inferior e a aresta inferior da caixa é a amplitude em que $25 \%$ das variações mais baixas podem ser encontradas (quartil inferior). A distância entre a linha horizontal superior e a aresta superior da caixa mostra o intervalo em que $25 \%$ das variações mais altas podem ser encontradas (quartil superior). Observa-se no diagrama a variação mediana bem próxima de 10\% para a variação média do período de 1980 a 2014, enquanto a maior variação foi superior a $40 \%$ e a menor aproximou-se de zero. 
Figura 1 - Diagrama de boxplot do conjunto das variações da execução por função orçamentaria entre 1980 e 2014

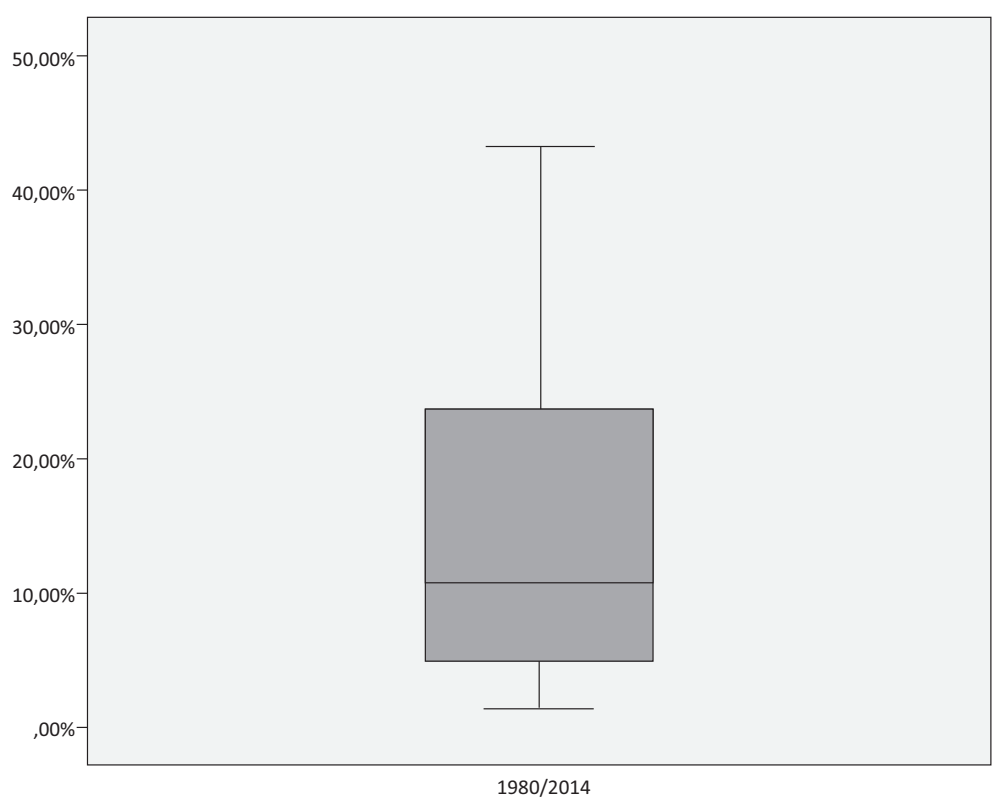

Fonte: Elaboração própria.

Para verificar o comportamento da variação ano a ano de 1980 a 2014, elaborouse o diagrama de boxplot - Figura 2. Nesse caso, é possível verificar a existência de variações que apresentam um grande afastamento das demais (outliers). Dessas, apenas 12 variações das 510 observações apresentaram valores superiores a $200 \%$. As maiores amplitudes de variações observadas no diagrama ocorreram entre 1985 e 1986, 1988 e 1989 e de 1989 e 1990. No período de 1996 a 2014, notou-se redução na amplitude das caixas e dos "bigodes", indicando expressiva redução das variações da execução orçamentária por função.

Sendo assim, vale ressaltar que essas observações estão alinhadas ao que foi proposto pelas teorias que buscam explicar as mudanças nas políticas públicas, como a Teoria dos Múltiplos Fluxos e o Equilíbrio Pontuado. Ademais, as observações permitem a construção de um conjunto de questões, hipóteses e reflexões que podem orientar investigações futuras sobre mudanças em políticas públicas no Brasil.

Em 1986, segundo ano do Governo Sarney, foi executado o primeiro orçamento elaborado por um governo civil após o Regime Militar. O aumento da amplitude das variações da execução orçamentária por função pode estar relacionado a essa importante mudança institucional.

Outra mudança institucional de grande magnitude, a promulgação da Constituição Federal em 1988, foi seguida por um ano de fortes variações na execução orçamentária. Além disso, 1989 foi o ano da primeira eleição direta e democrática 
para presidente após o Regime Militar. Sendo assim, em que medida esse novo arcabouço institucional, a competição política e os novos direitos assegurados pela nova Carta viabilizaram a ocorrência de mudanças significativas nas políticas públicas naquele ano? Novamente, em 1990 o primeiro ano do Governo Collor, primeiro governo eleito democraticamente após a redemocratização, com o início de reformas significativas, foi acompanhado por expressivas variações na execução orçamentária por funções.

Por sua vez, um movimento de redução da amplitude de variação da execução orçamentária por funções é observado no período posterior a 1996 até o período de 2014. Estudos mais profundos podem ser realizados para verificar se a relação entre essa acomodação das variações orçamentárias está relacionada com a mudança institucional advinda da estabilidade monetária promovida pelo Plano Real.

Esses eventos são apontados por Davis, Dempster e Wildavsky (1966), Baumgartner e Jones (1993) e Kingdon (2011) como fatores que podem promover as mudanças bruscas, terremotos e janelas políticas. Em especial, a Teoria do Equilíbrio Pontuado enfoca a interação entre instituições e imagens das políticas para explicar o equilíbrio e as rupturas. Nesse caso, estudos posteriores devem considerar não apenas as mudanças institucionais apresentadas, mas também eventuais mudanças nas imagens das políticas, que possibilitariam sua ascensão à macropolítica. A investigação mais aprofundada desses períodos poderia comprovar a existência de terremotos e consolidar a abordagem da Teoria do Equilíbrio Pontuado para o Brasil.

\section{Figura 2 - Diagrama de boxplot com a variação anual entre 1980 e 2014}

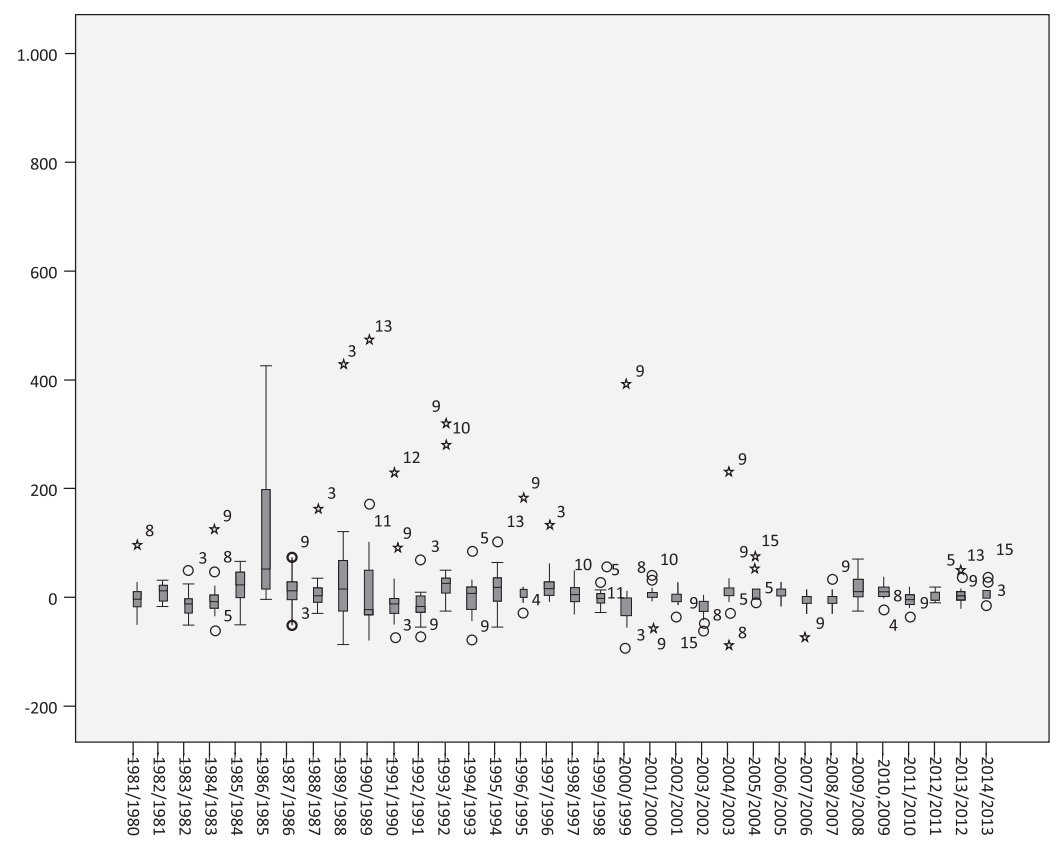

Fonte: Elaboração própria. 
Outra forma de validar a aplicação da Teoria do Equilíbrio Pontuado é por meio da análise da destruição das variações. De acordo com Field (2010), o grau de achatamento da curva de frequência pode ser normal com formato de sino, unimodal e simétrica em relação à sua média. Já a curva não normal com formato assimétrico pode ser mais afilada com o pico elevado (chamada de leptocúrtica) ou apresentar pico achatado (chamada de platicúrtica). Bryan, Baumgartner e Jones (2007) levantam a hipótese de que a distribuição para as variações anuais do orçamento em todos os níveis de agregação é não normal e apresenta características leptocúrticas, sob a lente da Teoria do Equilíbrio Pontuado.

Para verificar essa hipótese, elaborou-se o histograma com a variação da execução das funções orçamentária da União para o período de 1980 a 2014 (Figura 3), e foi constatado que a frequência da variação não configura uma distribuição normal, ou seja, percebe-se um comportamento não normal com formato assimétrico e mais afilado que representa uma distribuição leptocúrtica. De acordo com Field (2010), foram realizados os testes Kolmogorov-Smirnov e Shapiro-Wilk de normalidade, que apresentaram significância 0,00 e comprovam a não normalidade da curva de frequência - Tabela 3.

Os dados apresentados na Figura 3 incluem as 12, das 510 variações observadas, que apresentam um grande afastamento das demais, ou seja, outliers com variações superiores a $200 \%$. Sem fazer a eliminação desses dados, a média de variação observada foi de 13,81\% com desvio padrão de $76,72 \%$. A menor variação observada foi $-94,17 \%$ e a maior foi de $848,36 \%$ com uma amplitude observada de 942,53\%. Esse resultado confirma a hipótese de Bryan, Baumgartner e Jones (2007), segundo a qual variações orçamentárias anuais apresentam distribuição leptocúrtica, ou seja, uma distribuição com um pico central delgado demonstrando a lógica da estabilidade, ocorrência relativamente baixa de mudanças moderadas e, nas caudas, a ocorrência das pontuações orçamentárias. 
Figura 3 - Histograma de frequência das variações orçamentárias por função entre 1980 e 2014

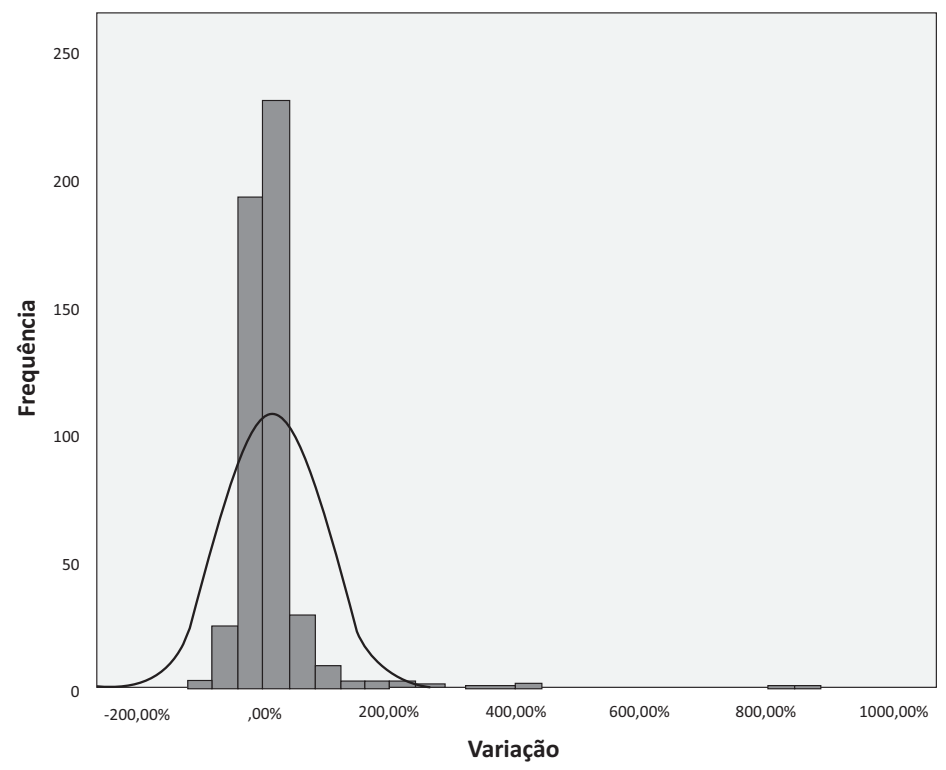

Fonte: Elaboração própria.

Tabela 3 - Teste de normalidade das variações orçamentárias por função entre 1980 e 2014

\begin{tabular}{l|l|l|l|l|l|l}
\hline \multirow{4}{*}{} & \multicolumn{3}{|l|}{ Kolmogorov-Smirnova } & \multicolumn{2}{l}{ Shapiro-Wilk } \\
\cline { 2 - 7 } & Estatística & df & Significância & Estatística & df & Significância \\
\hline Variação & 0,274 & 510 & 0,000 & 0,462 & 510 & 0,000 \\
\hline
\end{tabular}

a. Lilliefors Significance Correction

Fonte: Elaboração própria.

Embora a execução da análise com as 12 variações que representam outliers, com variações superiores a $200 \%$, não tenha prejudicado os resultados do estudo e a confirmação da hipótese de Bryan, Baumgartner e Jones (2007), será apresentado histograma e resultados descritivos com a eliminação dos outliers na Figura 4 e na Tabela 4. Após a eliminação dos outliers superiores a 200\%, a média de variação observada foi de 4,23\% com desvio padrão de 33,16\%. A menor variação continua apresentado o valor de $-94,17 \%$ e a maior foi de $183,71 \%$, com amplitude de observada de $277,88 \%$. Os testes Kolmogorov-Smirnov e Shapiro-Wilk de normalidade continuaram apresentando significância 0,00 e comprovando não normalidade da curva de frequência - Tabela 4. 
Figura 4 - Histograma de frequência das variações orçamentárias por função, excluídos os outliers, entre 1980 e 2014

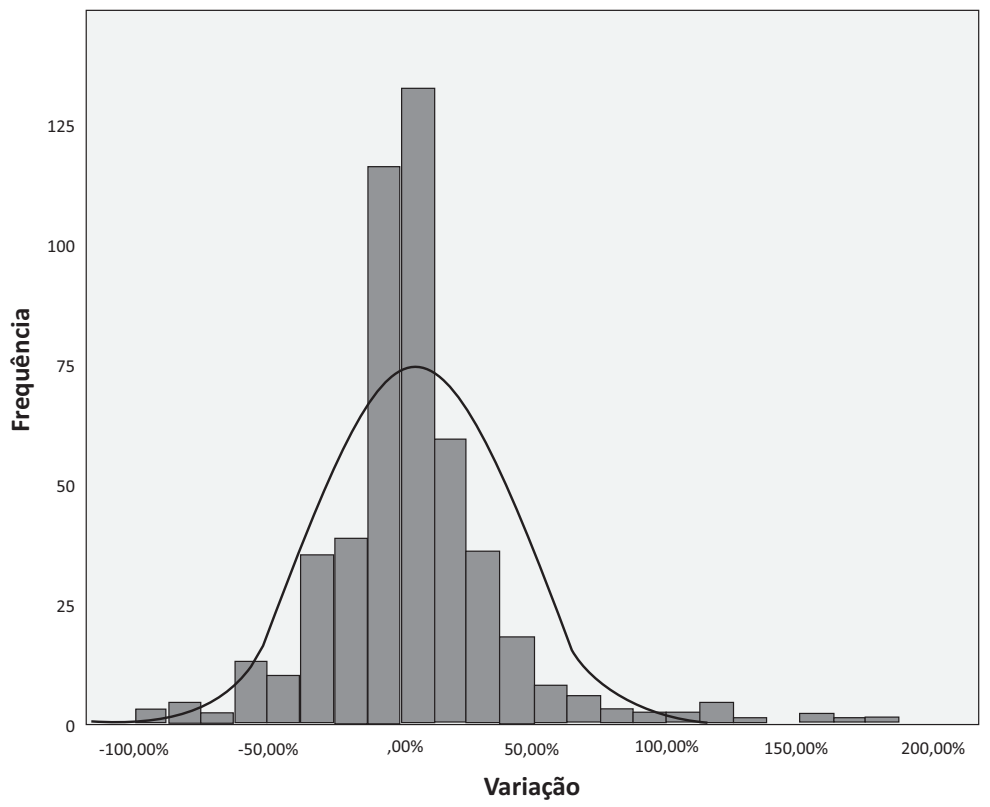

Fonte: Elaboração própria.

Tabela 4 - Teste de normalidade das variações orçamentárias por função, excluídos os outliers, entre 1980 e 2014

\section{Teste de Normalidade}

\begin{tabular}{l|l|l|l|l|l|l}
\hline \multirow{4}{*}{} & \multicolumn{3}{|l|}{ Kolmogorov-Smirnov ${ }^{\text {a }}$} & \multicolumn{2}{l}{ Shapiro-Wilk } \\
\cline { 2 - 8 } & Estatística & df & Significância & Estatística & df & Significância \\
\hline Variação & 0,131 & 498 & 0,000 & 0,887 & 498 & 0,000 \\
\hline
\end{tabular}

a. Lilliefors Significance Correction

Fonte: Elaboração própria.

Os outliers podem representar "terremotos" ou mudanças bruscas na execução de políticas públicas e apontam para a possibilidade de investigações e estudos futuros sobre essas pontuações do equilíbrio. Dessa forma, o estudo apresenta uma tabela com o ano, a função orçamentária e variação orçamentária de possíveis terremotos para serem melhor investigados - Tabela 5.

Esta análise indica a confirmação da hipótese da Teoria do Equilíbrio Pontuado para o orçamento federal no Brasil, em que a distribuição de frequência das variações na execução das políticas públicas, por meio do orçamento, apresenta 
comportamento de não normalidade com formato assimétrico e claramente leptocúrtico, como observado nas Figuras 3 e 4.

Tabela 5 - Outliers superiores a $200 \%$ observados na amostra estudada

\begin{tabular}{l|l|l}
\hline Ano & Fonte & $\begin{array}{l}\text { Variação em relação ao } \\
\text { ano anterior }\end{array}$ \\
\hline 1986 & Administração e Planejamento & $237,27 \%$ \\
\hline 1986 & Agricultura & $251,30 \%$ \\
\hline 1986 & Habitação e Urbanismo & $425,50 \%$ \\
\hline 1986 & Indústria, Comércio e Serviços & $814,89 \%$ \\
\hline 1989 & Administração e Planejamento & $432,26 \%$ \\
\hline 1990 & Trabalho & $475,42 \%$ \\
\hline 1991 & Saúde e Saneamento & $227,27 \%$ \\
\hline 1993 & Indústria, Comércio e Serviços & $279,78 \%$ \\
\hline 1993 & Habitação e Urbanismo & $320,96 \%$ \\
\hline 2000 & Habitação e Urbanismo & $392,97 \%$ \\
\hline 2002 & Energia e Recursos Minerais & $848,36 \%$ \\
\hline 2004 & Habitação e Urbanismo & $230,59 \%$ \\
\hline
\end{tabular}

Fonte: Elaboração própria.

Além disso, os dados permitem ainda uma avaliação da estrutura das variações por função - Tabela 6. Pode-se considerar que as funções que apresentaram comportamento de maior estabilidade foram as funções Legislativa, Assistência e Previdência, Defesa Nacional e Segurança Pública, e Judiciária, as quais possuem o maior número de variações em torno de zero (entre $10 \%$ negativo e $10 \%$ positivo), bem como não apresentaram variações extremas (superiores a $-50 \%$ e maiores do que $200 \%$ ).

Por outro lado, as funções menos estáveis foram as de Habitação e Urbanismo; Indústria, Comércio e Serviços; Transporte; e Energia e Recursos Minerais. Essas funções apresentaram o menor número de variações em torno de zero, assim como concentraram mais de $60 \%$ das variações extremas.

Nesse sentido, abre-se um leque de possibilidade de estudos comparativos entre as funções (ou temas de políticas públicas) para identificar que fatores contribuem para que uma determinada função seja objeto de um número maior ou menor de mudanças significativas (terremotos). Em síntese, a Teoria do Equilíbrio Pontuado pode ser útil para entender que fatores contribuem para que determinados subsistemas sejam mais ou menos estáveis, com monopólios de política mais ou menos fortes, com maior ou menor probabilidade de alcançar a macropolítica. 
Tabela 6 - Quantidade de variações anuais da execução orçamentária por função orçamentária entre 1980 e 1981, por tamanho da variação

\begin{tabular}{|c|c|c|c|c|c|c|c|c|}
\hline FUNÇÃO & $\begin{array}{l}\text { Redução } \\
\text { maior } \\
\text { que } 50 \%\end{array}$ & $\begin{array}{l}\text { Redução } \\
\text { maior } \\
\text { que } 30 \% \\
\text { e menor } \\
\text { ou igual } \\
\text { a 50\% }\end{array}$ & $\begin{array}{l}\text { Redução } \\
\text { maior } \\
\text { que } 10 \% \\
\text { e menor } \\
\text { ou igual } \\
\text { a } 30 \%\end{array}$ & $\begin{array}{l}\text { Redução } \\
\text { menor ou } \\
\text { igual a 10\% } \\
\text { ou aumen- } \\
\text { to menor } \\
\text { ou igual a } \\
10 \%\end{array}$ & $\begin{array}{l}\text { Aumento } \\
\text { maior } \\
\text { que } 10 \% \\
\text { e menor } \\
\text { ou igual } \\
\text { a } 30 \%\end{array}$ & $\begin{array}{l}\text { Aumento } \\
\text { maior } \\
\text { que } 30 \% \\
\text { e menor } \\
\text { ou igual a } \\
50 \%\end{array}$ & $\begin{array}{l}\text { Aumento } \\
\text { maior } \\
\text { que } 50 \% \\
\text { e menor } \\
\text { ou igual } \\
\text { a } 200 \%\end{array}$ & $\begin{array}{l}\text { Aumento } \\
\text { maior } \\
\text { que } 200 \%\end{array}$ \\
\hline Legislativa & 0 & 0 & 3 & 23 & 6 & 1 & 1 & 0 \\
\hline Judiciária & 0 & 0 & 4 & 18 & 6 & 4 & 2 & 0 \\
\hline $\begin{array}{l}\text { Administração } \\
\text { e } \\
\text { Planejamento }\end{array}$ & 4 & 1 & 5 & 12 & 5 & 1 & 4 & 2 \\
\hline Agricultura & 0 & 4 & 7 & 13 & 5 & 3 & 1 & 1 \\
\hline Comunicações & 1 & 4 & 4 & 15 & 5 & 2 & 3 & 0 \\
\hline $\begin{array}{l}\text { Defesa } \\
\text { Nacional e } \\
\text { Segurança } \\
\text { Pública }\end{array}$ & 0 & 0 & 6 & 19 & 8 & 1 & 0 & 0 \\
\hline $\begin{array}{l}\text { Educação e } \\
\text { Cultura }\end{array}$ & 0 & 1 & 5 & 15 & 9 & 4 & 0 & 0 \\
\hline $\begin{array}{l}\text { Energia e } \\
\text { Recursos } \\
\text { Minerais }\end{array}$ & 5 & 1 & 4 & 11 & 8 & 2 & 2 & 1 \\
\hline $\begin{array}{l}\text { Habitação e } \\
\text { Urbanismo }\end{array}$ & 5 & 5 & 4 & 4 & 3 & 3 & 6 & 4 \\
\hline $\begin{array}{l}\text { Indústria, } \\
\text { Comércio e } \\
\text { Serviços }\end{array}$ & 3 & 5 & 7 & 9 & 3 & 4 & 1 & 2 \\
\hline $\begin{array}{l}\text { Relações } \\
\text { Exteriores }\end{array}$ & 2 & 1 & 4 & 14 & 10 & 2 & 1 & 0 \\
\hline $\begin{array}{l}\text { Saúde e } \\
\text { Saneamento }\end{array}$ & 0 & 1 & 4 & 18 & 6 & 2 & 2 & 1 \\
\hline Trabalho & 0 & 2 & 2 & 17 & 6 & 3 & 3 & 1 \\
\hline $\begin{array}{l}\text { Assistência e } \\
\text { Previdência }\end{array}$ & 0 & 1 & 0 & 22 & 8 & 1 & 2 & 0 \\
\hline Transporte & 2 & 0 & 10 & 11 & 8 & 1 & 2 & 0 \\
\hline Total & 22 & 26 & 69 & 221 & 96 & 34 & 30 & 12 \\
\hline
\end{tabular}

Fonte: Elaboração própria. 


\section{Considerações finais}

Por fim, este trabalho verificou a aderência da Teoria do Equilíbrio Pontuado na execução orçamentária da União e identificou os períodos de variações atípicas nas diversas áreas do Governo Federal. Feita essa análise, ficou perceptível um padrão de equilíbrio com interrupções, corroborando a hipótese central de que a Teoria do Equilíbrio Pontuado é válida para analisar o comportamento das variações orçamentárias no Brasil.

Esta conclusão abre caminho para um conjunto de novos estudos, que visem aprofundar a análise de mudanças nas políticas públicas por meio do orçamento, evidenciando a dinâmica de interação entre as instituições, suas transformações e o processamento de informações para a construção da imagem da política, gerando feedbacks positivos ou negativos, reforçando monopólios em subsistemas de políticas ou contestando-os, com a elevação das questões de política pública à agenda macropolítica.

Um ponto de partida para esses novos estudos podem ser as pontuações significativas verificadas em 1986, 1989 e 1990, assim como a predominância de situações de equilíbrio evidenciadas a partir de 1996. Em 1986 foi executado o primeiro orçamento elaborado por um governo civil após o Regime Militar; em 1988 a promulgação da Constituição Federal trouxe novos acordos em torno das políticas que seriam executadas a partir de 1989, ano da primeira eleição direta e democrática para presidente após o Regime Militar. O primeiro ano de um governo eleito democraticamente após a redemocratização foi 1990, com o início de reformas significativas.

A redução da amplitude de variação da execução orçamentária por funções é observada no período posterior a 1996 até o período de 2014 e pode indicar a acomodação das variações orçamentárias advinda da estabilidade monetária promovida pelo Plano Real.

Dessa forma, acredita-se que o desenvolvimento dessa nova agenda de pesquisa representa um avanço nos estudos de políticas públicas e orçamento no Brasil, uma vez que grande parte dos estudos orçamentários não utiliza modelos teóricos para examinar e compreender o comportamento das decisões no processo orçamentário. 


\section{Referências bibliográficas}

Abreu, Welles M.; NeIVA, Vinícius M.; LIMA, Nerylson. Modelos de tomada de decisão no processo orçamentário brasileiro: uma agenda de pesquisas. Revista do Serviço Público, Brasília,v. 63, n. 2, p. 135-155, abr./jun. 2012.

BAK, P. How nature works. New York: Springer-Verlag, 1997.

BAK, P.; CHEN, K. Self-organized criticality. Scientific American, v. 264, p. 46-53, 1991.

BAUMgartner, F. R.; Jones, B. D. Agenda dynamics and policy subsystems. Journal of Politics, v. 53, p. 1044-1074, 1991.

Agendas and instability in American politics. Chicago: University of Chicago Press, 1993.

From there to here: Punctuated Equilibrium to the General Punctuation Thesis to a Theory of Government Information Processing. The Journal of Politics, v. 60, p. 1-33, 1998.

Baumgartner, F. R.; Jones, B. D.; TRUe, J. L. Punctuated Equilibrium Theory. Theories of the Policy Process. Colorado: Westview Press, 2007.

BonAfOnt, L. C. Redes de políticas públicas. Madrid: Centro de Investigaciones Sociológicas, 2004.

Bosso, C. J. Pesticides and politics: the life cycle of a public issue. Pittsburgh: University of Pittsburgh Press, 1987.

CAPELLA, A. C. N. Perspectivas teóricas sobre o processo de formulação de políticas públicas. Revista Brasileira de Informação Bibliográfica em Ciências Sociais (BIB), São Paulo, n. 61, p. 25-52, 2006.

Coвb, R. W.; Charles, D. E. Participation in American politics: the dynamics of agenda-building. Baltimore: Johns Hopkins University Press, 1983.

Совв, R. W.; Ross, M. H. Cultural strategies of agenda denial. Lawrence: University of Kansas Press, 1997.

Davis, O. A; Dempster, M. A. H.; Wildavsky, A. A. Theory of the Budgetary Process. The American Political Science Review, v. 60, p. 529-547, 1966.

FIELD, A. Discovering statistics using SPSS. London: Sage, 2010.

FontAINE, G. Lecciones de América Latina sobre las dimensiones racionales, cognitivas e institucionales del cambio de políticas Presentación del dossier. Íconos. Revista de Ciencias Sociales, n.53, p. 11-30, 2015.

GIVEL, M. The evolution of the Theoretical Foundations of Punctuated Equilibrium in public policy. Review of Policy Research, v. 17, p. 187-198, 2010.

GROTH, P.; GURNEY, T. Studying scientific discourse on the Web using bibliometrics: a chemistry blogging case study". Web Science Conf, Raleigh, NC, USA, p. 26-27, 2010. JONES, B. D. Reconceiving decision-making in democratic politics: attention, choice, and public policy. Chicago: University of Chicago Press, 1994.

Jones, B. D; BAumgartner, F. R.; TRUe, J. L. Policy punctuated: U.S. budget authority, 1947-1995. The Policy Studies Journal, p. 1-19, 2012. 
KINGDON, J. W. Agendas, alternatives and public policies. Boston: Longman, 2011. LINDBlom, C. The science of "muddling through." Public Administration Review, v. 19, n. 2, p. 79-88, 1959.

Ollaik, L. G; Wenceslau, J.; Serpa, S. M. H. C.; Medeiros, J. J. Novas direções para pesquisas orçamentárias no Brasil”. Revista de Políticas Públicas, v. 15, p. 347-357, 2011.

Ostrom JR, Charles W.; MarRA, Robin F. A Reactive Linkage Model of the U.S. defense expenditure policymaking process". American Political Science Review, v. 72, p. 941-957, 1986.

RoBINSON, S.; WARREN, E. Participation in policy streams: testing the separation of problems and solutions in subnational policy systems. The Policy Studies Journal, p. 199-215, 2010.

SCHATTSCHNEIDER, E. E. The semi-sovereign people. New York: Holt, Rinehart \& Winston, 1960.

Silva, Rosane M. P.; BandeIRA, Ludmila F.; Alfinito, Solange; Calmon, Paulo C. D. P.; GonçAlves, Andrea O. Teoria do Equilíbrio Pontuado: um estudo aplicado no Orçamento Criança Adolescente. In: EnCONTRO DA ENANPAD, 34, Belo Horizonte, 13 a 16 de setembro de 2016.

Silvestre, Hugo; Araúso, Joaquim. Teoria do Equilíbrio Pontuado nas políticas públicas brasileiras: o caso do Ceará. Revista de Administração Científica, Rio de Janeiro, v. 19, n. 6, p. 696-711, nov./dez. 2015.

Simon, H. A. Models of man. New York: Wiley, 1957.

The logic of heuristic decision-making. In: COHEN, R. S.; WARTOFSKY, M.

W. (Eds.). Models of Discovery. Boston: D. Reidel, 1977.

Reason in human affairs. Stanford: Stanford University Press, 1983.

Human nature in politics: the dialogue of Psychology with Political

Science. American Political Science Review, v. 79, p. 293-304, 1985.

SWAIN, J.; HARTLEY, C. J. Incrementalism: old but good? In: BARTLE, J. (Org.). Envolving theories of public budgeting. Amsterdam: Elsevier Science, 2001. p. 11-28

TRUE, J. et al. Punctuated-Equilibrium Theory: explaining stability and change in public policy making. In: SABATIER, P. (Ed.). Theories of the policy process. Boulder: Westview Press, 2007.

ZAHARIADIS, N. Multiple Streams Framework: structure, limitations and prospects. In: SABATIER, P. (Ed.). Theories of the policy process. Boulder: Westview Press, 2007.

Daniel Izaias de Carvalho

Doutorando em Administração na UnB, Mestre em Administração Pública (UnB), Especialista em Estatística (UDF), Especialista em Finanças (Upis) e Bacharel em Ciências Contábeis (Upis). Atualmente é Auditor de Controle Interno do Distrito Federal e professor de Contabilidade Avançada na União Pioneira de Integração Social (Upis).

Contato: danizalho@gmail.com 
